\title{
Distally Based Sural Flap in Children: Reliability Technique
}

A. Benjelloun, N. Belmoudden, M. Habla, M. Benkhaldoun, A. Elharti and M. Diouri

\section{ABSTRACT}

The distally based sural flap often poses the problem of venous suffering that can lead to necrosis. We present a reconstruction of a loss of substance of the ankle in a 6 years old child, using a distal pedicle sural flap, made reliable by a racket like flap method, which reduces the risk of vascular complications and led to good integration of the flap, with a good functional result. Nevertheless, the aesthetic sequelae remain significant.

Keywords: Children, reliability, sural flap, technique.

Submitted: August 15, 2021

Published: October 14, 2021

ISSN: $2593-8339$

DOI: 10.24018 /ejmed.2021.3.5.1015

\section{A. Benjelloun*}

Department of Plastic Surgery, UHC Ibn Rochd, Casablanca, Morocco.

(e-mail: ben-anas@hotmail.com)

N. Belmoudden

Department of Plastic Surgery, UHC Ibn Rochd, Casablanca, Morocco.

M. Habla

Department of Plastic Surgery, UHC Ibn Rochd, Casablanca, Morocco.

M. Benkhaldoun

Department of Plastic Surgery, UHC

Ibn Rochd, Casablanca, Morocco.

A. Elharti

Department of Plastic Surgery, UHC

Ibn Rochd, Casablanca, Morocco.

M. Diouri

Department of Plastic Surgery, UHC

Ibn Rochd, Casablanca, Morocco.

*Corresponding Author

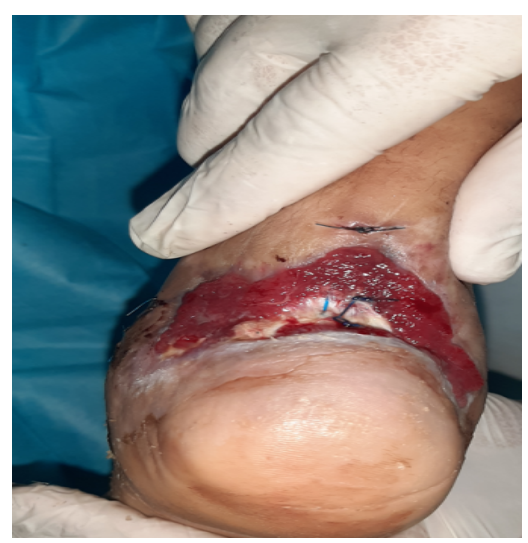

Fig. 1. Substance loss.

Female child, 6 years old, with no particular pathological history, presenting a loss of substance of the ankle with exposure of the Achilles tendon (Fig. 1), following an MVA, initially managed in pediatric traumatology for trimming and suture of the Achilles tendon, then referred to us for coverage.

On the clinical examination: $7 \mathrm{~cm} \times 4 \mathrm{~cm} \mathrm{SDB}$ on the posterior aspect of the ankle / Dorsiflexion limited to $100^{\circ}$ / Plantar flexion retained.

Ankle X-ray: No fracture.

\section{INTRODUCTION}

The distally based sural neurocutaneous flap is often indicated for the coverage of distal substance losses of the lower limb during bone or tendon exposure. Different the case of a 6 years old child who benefited from this flap harvested in racket method, which allows for its reliability.

\section{CASE REPORT}


of the racket flap with a subcutaneous pedicle extending beyond the handle by $2 \mathrm{~cm}$ on each side, to enable a better venous return.

The procedure is performed under garrote.

The flap is lifted, taking the lesser saphenous vein and the medial sural nerve in its pedicle (Fig. 3).

The intermediate site between the pivot point and the loss of substance is incised, the skin edges are lifted to allow the pedicle to pass, and the skin paddle of the handle is sutured to the skin edges of the intermediate site. The useful paddle of the flap is sutured in one plane (Fig. 4).

The donor area is grafted after budding with split thickness skin grafts taken from the thigh.

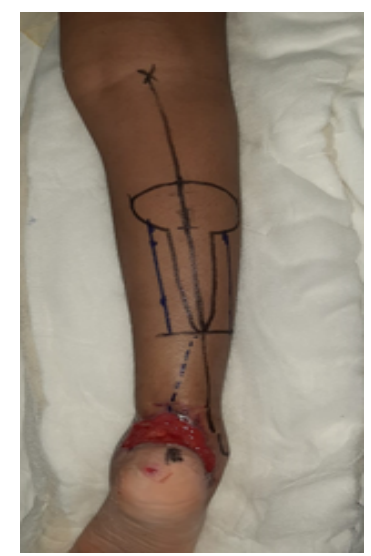

Fig. 2. Pre-operative tracing.

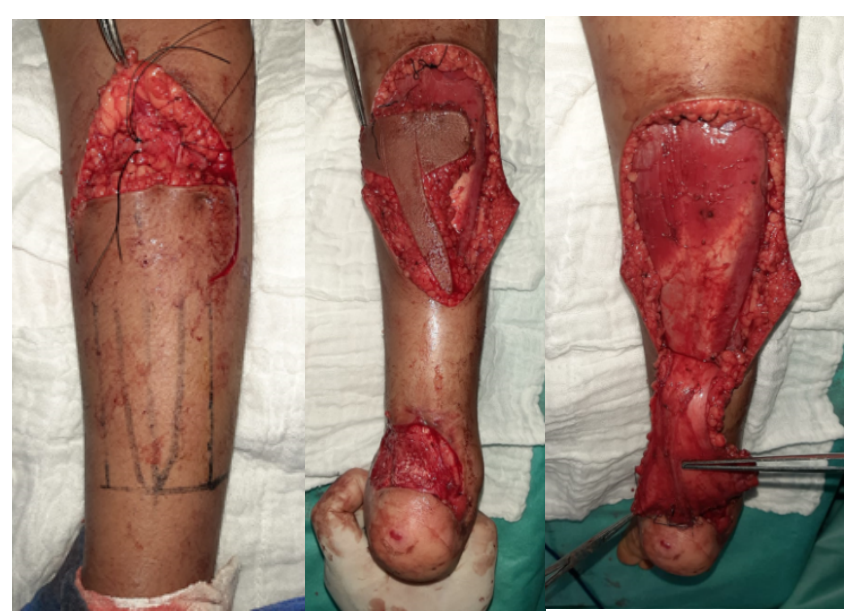

Fig. 3. Flap lift after identifying the pedicle.

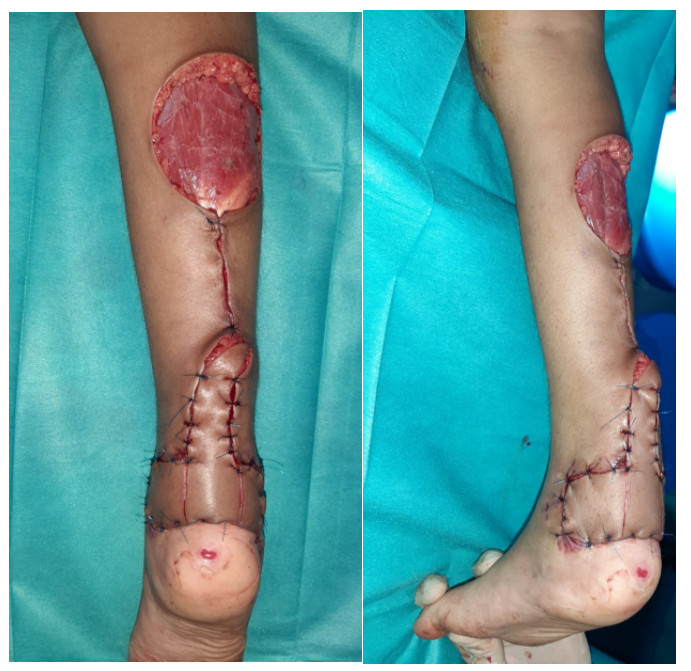

Fig. 4. Placement of the flap.

\section{Post-Operative Follow-Up}

The evolution was marked by a good integration of the flap and a satisfactory functional result after physical therapy.

No early complications.

Easthetic sequelae (Fig. 5):

- Hypertrophic scars at 2 months post-operatively at the flap edges, graft edges and split thickness skin grafts donor area, currently treated with pressotherapy.

- Thick flap that can be defatted later.

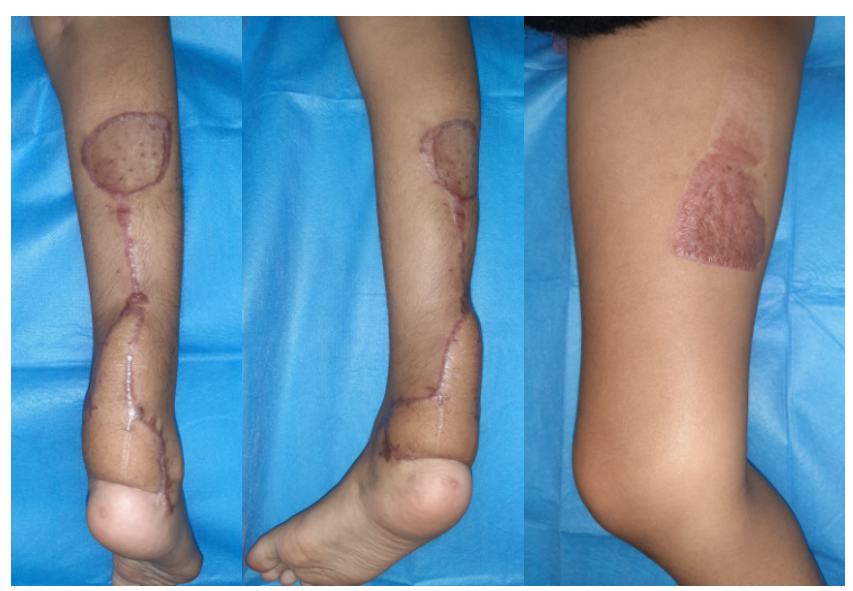

Fig. 5.2 months post-operative results.

\section{DISCUSSION}

The advantages of the distally based sural flap in this case are:

- Reliability especially within the framework of the racket like method: C.-S. Bich in a study compared 14 sural flaps with distal pedicles taken in racket with 9 tunnellated, had 2 cases of venous suffering and one case of partial necrosis for the latter, against none for the flaps taken in racket.

- Reproducibility.

- Padding of the area that allows a stable scar when wearing shoes.

- Best functional result for the ankle.

- Better evolution in a growing child.

The aesthetic consequences of the donor area remain a disadvantage of this flap, especially in a little girl.

J. Fernandez proposed to reduce these consequences by removing skin from one of the two skin flaps in the intermediate zone to cover the donor zone. This choice was not made in our case, as we would not have had sufficient laxity to suture the intermediate zone.

\section{CONCLUSION}

The distally based sural flap is a technique of choice for coverage of ankle loss of substance with exposure of the Achilles tendon in pediatric practice. The "racketlike" technique makes these flaps more reliable by reducing the risk of necrosis due to venous engorgement of the flap. It is a simple, reliable, effective, and easily reproducible technique. 


\section{REFERENCES}

[1] C.S. Bich, M. Brachet, A. Baus, A. Duhoux, P. Duhamel and É. Bey. "The "racket-like" flap: Method to increase the reliability of the sural neuro-cutaneous flap," Ann Chir Plast Esthet 65, 300-305, 2020.

[2] J. Fernandez, C. Clérico, O. Camuzard and B. Chignon-Sicard. "New cutaneous strategy in sural flap surgery and possibility to adapt this technique to otherpedic led flaps," Ann Chir Plast Esthet 60, 316-320, 2015.

[3] A. Grandjean, C. Romana and F. Fitoussi, "Distally based sural flap for ankle and foot coverage in children," Rev Chir Ortho Traumato 101, $175-176,2015$. 